\title{
A VIOLAÇÃO DO PRINCÍPIO DA PROIBIÇÃO DO RETROCESSO DA LEI AMBIENTAL NA REGIÃO DO CANTO DO MORCEGO, ITAJAÍ - SC
}

\author{
A INFRINGEMENT OF THE PRINCIPLE OF ENTRENCHED CLAUSE OF \\ ENVIRONMENTAL LEGISLATION IN THE REGION OF THE CANTO DO \\ MORCEGO, ITAJAÍ - SC
}

Sabrina Schneider ${ }^{1}$ Caroline Vieira Ruschel ${ }^{2}$

SUMÁRIO: Introdução; 1. Entendendo o Princípio da Proibição do Retrocesso da lei ambiental; 2. Praia Brava e Canto do Morcego - Itajaí, SC: Ocupação e Degradação; 3. Análise: Leis Complementares no 94/2006 e no 216/2012; 3.1. Breve histórico; 3.2. Análise das Leis Complementares no 94/2006 e no 216/2012 à luz do Princípio da Proibição do Retrocesso da lei ambiental; Considerações Finais; Referências Bibliográficas.

RESUMO: O Direito Ambiental, amplamente discutido na atualidade e em constante processo de desenvolvimento e melhorias, se vê diariamente ameaçado por fatores políticos, econômicos, jurídicos e até mesmo psicológicos. A alteração de leis que têm como missão maior a salvaguarda do meio ambiente coloca em risco anos de discussão e avanços, trazendo a tona um evidente retrocesso ambiental. O Canto do Morcego, situado na Praia Brava, Itajaí - SC corre o risco de ver desaparecer seu sensível ecossistema devido a não observância do Princípio da proibição do retrocesso da lei ambiental. O presente artigo tem como objetivo destacar a importância do referido princípio através de uma análise comparativa de duas legislações do município de Itajaí responsáveis pela regulamentação das políticas de desenvolvimento urbano locais: as Leis Complementares no 94/2006 e no 215/2012 - o Plano Diretor de Gestão e Desenvolvimento Territorial e a Lei de Zoneamento, parcelamento e uso do solo,

\footnotetext{
${ }^{1}$ Bacharel em Direito pela Universidade do Vale do Itajaí, campus Itajaí; endereço eletrônico email dabina@hotmail.com

2 Mestre em Direito pela Universidade Federal de Santa Catarina; advogada; Professora de Direito Ambiental na Universidade do Vale do Itajaí; Graduada em Ciências Jurídicas e Sociais pela Pontifícia Universidade Católica do Rio Grande do Sul; endereço eletrônico caroline.ruschel@univali.br
} 
SCHNEIDER, Sabrina; RUSCHEL, Caroline Vieira. A violação do princípio da proibição do retrocesso da lei ambiental na região do Canto do Morcego, Itajaí - SC. Revista Eletrônica Direito e Política, Programa de Pós-Graduação Stricto Sensu em Ciência Jurídica da UNIVALI, Itajaí, v.10, n.1, edição especial de 2015. Disponível em: www.univali.br/direitoepolitica - ISSN 1980-7791.

respectivamente. A análise proposta, realizada por meio do método indutivo, se limita à Praia Brava, mais especificadamente ao Canto Norte, região conhecida como Canto do Morcego, por ser alvo de um conflito territorial e social que se arrasta há anos, paralelo à degradação diária da região, valiosa em recursos naturais.

Palavras-chave: Plano diretor de Gestão e Desenvolvimento Territorial; Princípio da proibição do retrocesso ambiental; Macrozoneamento; Zoneamento.

ABSTRACT: Environmental Law, widely discussed in the news and in a constant process of development and improvement, is daily threatened by political, economic, legal and even psychological factors. Changing laws whose larger mission to safeguard the environment jeopardizes years of discussion and progress, bringing out a clear environmental backlash. The Canto do Morcego, situated in Praia Brava, Itajai - SC runs the risk of disappearing due to its sensitive ecosystem because of no observing the Entrenched clause of environmental legislation. This article aims to highlight the importance of this principle through a comparative analysis of two laws of Itajaí responsible for regulating policies of local urban development: Complementary Law No. 94/2006 and No. 215/2012 - the Master Plan Management and Land Development and Zoning Law, installment and land use, respectively. The proposed analysis, performed using the inductive method, is limited to Praia Brava, more specifically the North Corner, Corner region known as the Morcego, by being the target of a territorial and social conflict that has dragged on for years, parallel to the daily degradation of the region, valuable in natural resources.

Keywords: Director Management Plan and Territorial Development; Entrenched clause; Macrozoning; Zoning.

\section{INTRODUÇÃO}

A evolução do ser humano através do tempo trouxe em sua bagagem um mal inevitável: a degradação do meio ambiente. Num período relativamente curto ocorreu um despertar mundial com a finalidade de discutir e agir para que se minimizem tais impactos causados pela evolução humana. O despertar, mesmo tardio, com seus primeiros sintomas observados há aproximadamente 50 anos ${ }^{3}$, trouxe inúmeros benefícios na construção de uma consciência coletiva voltada às

\footnotetext{
${ }^{3}$ A publicação do livro "A primavera silenciosa" de Rachel Carson, no ano de 1962 é considerado um dos grandes impulsos ao movimento ambiental. Nele a cientista fez um alerta sobre o uso de pesticidas sintéticos na agricultura. Mais informações disponíveis em A ONU e o Meio Ambiente :< http://www.onu.org.br/a-onu-em-acao/a-onu-e-o-meio-ambiente/>. Acesso em 20 mar. 2013.
} 
SCHNEIDER, Sabrina; RUSCHEL, Caroline Vieira. A violação do princípio da proibição do retrocesso da lei ambiental na região do Canto do Morcego, Itajaí - SC. Revista Eletrônica Direito e Política, Programa de Pós-Graduação Stricto Sensu em Ciência Jurídica da UNIVALI, Itajaí, v.10, n.1, edição especial de 2015. Disponível em: www.univali.br/direitoepolitica - ISSN 1980-7791.

preocupações ambientais. Mais do que estimular debates e uma nova consciência, esse lapso temporal deu origem a grandes progressos normativos ${ }^{4}$ com vistas à proteção ecológica.

Ocorre que após anos de pesquisas e avanços na área do direito ambiental, este se vê ameaçado por processos que ao invés de ampliarem a proteção dos ecossistemas, caminham no sentido contrário, trazendo à baila uma ameaça à sua substância, que poderia inclusive conduzir a um retrocesso legislativo e normativo potencialmente prejudicial ao homem e ao meio ambiente, já reconhecidos como interdependentes ${ }^{5}$. Tal retrocesso pode estar ocorrendo no município de Itajaí, SC. Uma lei de política urbana aprovada em dezembro de 2012 seria responsável por diminuir substancialmente a proteção de uma região conhecida como Canto do Morcego, localizada na porção norte da Praia Brava.

Com o intuito de demonstrar a importância do princípio da proibição do retrocesso da lei ambiental, o presente artigo tem por objetivo realizar através do método indutivo uma análise das Leis Complementares no 94/2006 e nº 215/2012 - Plano Diretor de Gestão e Desenvolvimento Territorial e a Lei de Zoneamento, parcelamento e uso do solo do município de Itajaí e seus respectivos Mapas e anexos, limitando-se geograficamente à região pertinente ao estudo (Canto do Morcego - porção norte da Praia Brava). Ambas as leis, que deveriam se complementar para efetivar a preservação da região do Canto do Morcego, teriam tornado-se contraditórias entre sim, já que a Lei de Zoneamento, parcelamento e uso do solo, de no 215/2012, posteriormente aprovada, seria responsável pela redução da proteção deste ecossistema.

Inicialmente, pretende-se realizar um breve aporte teórico sobre o Princípio da proibição do retrocesso da lei ambiental tendo como referencial teórico o autor Michel Prieur, grande estudioso do Direito Ambiental e entusiasta deste princípio.

\footnotetext{
${ }^{4}$ Documentos como a Declaração da Conferência das Nações Unidas sobre o Ambiente Humano (1972); o Relatório "Nosso futuro comum" (1987); a Agenda 21 (1992) e o Protocolo de Kyoto (1999) são exemplos de progressos ocorridos desde a década de 70. Mais informações disponíveis em A ONU e o Meio Ambiente:< http://www.onu.org.br/a-onu-em-acao/a-onu-e-o-meioambiente/>. Acesso em 20 mar. 2013.

5 PRIEUR, Michel. O princípio da "não regressão" no coração do direito do homem e do meio ambiente. Novos Estudos Jurídicos, Local da Publicação, v. 17, n. 1, p. 7. 2012.
} 
SCHNEIDER, Sabrina; RUSCHEL, Caroline Vieira. A violação do princípio da proibição do retrocesso da lei ambiental na região do Canto do Morcego, Itajaí - SC. Revista Eletrônica Direito e Política, Programa de Pós-Graduação Stricto Sensu em Ciência Jurídica da UNIVALI, Itajaí, v.10, n.1, edição especial de 2015. Disponível em: www.univali.br/direitoepolitica - ISSN 1980-7791.

Na sequência o estudo apresentará um relato da ocupação e degradação da Praia Brava e do Canto do Morcego, porção norte da praia, localizada no município de Itajaí - SC. Com base nos tópicos anteriores, pretende realizar um breve histórico da elaboração e aprovação das Leis Complementares no 94/2006, o Plano Diretor e no 215/2012, a Lei de Zoneamento, parcelamento e uso do solo do município de Itajaí, SC e posterior análise das respectivas leis, seus mapas e anexos, limitando-se à região conhecida como Canto do Morcego, à luz do princípio da proibição do retrocesso da lei ambiental.

\section{ENTENDENDO O PRINCÍPIO DA PROIBIÇÃO DO RETROCESSO DA LEI AMBIENTAL}

O Direito Ambiental evoluiu com o passar dos anos em decorrência da crescente preocupação da humanidade em preservar os ecossistemas da ação do próprio homem. Noberto Bobbio ${ }^{6}$ preleciona que "os direitos são construídos como barreiras de proteção a ameaças produzidas pelo aumento do poder do homem sobre o homem e do homem sobre a natureza $[\ldots]^{\prime \prime}$. Fato é que a preocupação humana, norteadora do Direito Ambiental, comunga de seu principal objetivo: contribuir com a redução de processos de poluição e com a preservação da biodiversidade $^{7}$. Nesse contexto, a preservação dos recursos naturais assume, então, destaque, visto que a degradação do meio ambiente, quando não contida, pode acarretar na impossibilidade de sobrevivência do homem. ${ }^{8}$

Ocorre que Direito Ambiental encontra-se ameaçado em sua substância, fato que poderia culminar em um recuo normativo. As ameaças são diversas: a) Jurídicas: visto que a teoria clássica do direito refuta a ideia de um direito adquirido às leis; b) Políticas: que surgem da vontade de simplificar o direito, devido ao número crescente de normas jurídicas ambientais; c) Econômicas: que ganham força

\footnotetext{
${ }^{6}$ BOBBIO, Norberto. A era dos direitos. Tradutor: Carlos Nelson Coutinho.8. ed. Rio de Janeiro: Campus/Elsevier, 1992.

7 PRIEUR, Michel. O princípio da "não regressão" no coração do direito do homem e do meio ambiente. Novos Estudos Jurídicos, Itajaí, v.17, n 1, p. 6-17, 2012.

8 MOLINARO, Carlos Alberto. Direito Ambiental: proibição de retrocesso. Porto Alegre: Livraria do Advogado Editora, 2007. p. 46.
} 
SCHNEIDER, Sabrina; RUSCHEL, Caroline Vieira. A violação do princípio da proibição do retrocesso da lei ambiental na região do Canto do Morcego, Itajaí - SC. Revista Eletrônica Direito e Política, Programa de Pós-Graduação Stricto Sensu em Ciência Jurídica da UNIVALI, Itajaí, v.10, n.1, edição especial de 2015. Disponível em: www.univali.br/direitoepolitica - ISSN 1980-7791.

graças à crise econômica mundial, favorecendo discursos que reclamam menos obrigações ambientais em prol do desenvolvimento e luta contra a pobreza; e d) Psicológicas: advindas da complexidade das normas, não acessível aos não especialistas. $^{9}$

Frente ao objetivo maior do Direito Ambiental - que corresponde ao interesse comum das sociedades - e às ameaças elencadas, surge a necessidade de se coibir o retrocesso das leis ambientais, num caminho de resguardo e proteção das conquistas normativas dos últimos anos e dos próprios recursos naturais.

No que concerne à terminologia deste princípio, a doutrina é hesitante e diversa. $\mathrm{Na}$ Bélgica utiliza-se o princípio do standstill. Na França utiliza-se o conceito de efeito cliquet (trava) ou cliquet anti-retour (trava anti-retorno); em inglês a expressão eternity clause ou entrenched clause; em espanhol prohibición de regressividad o de retrocesso; em português, proibição do retrocesso. ${ }^{10}$

Carlos Alberto Molinaro ${ }^{11}$ prefere utilizar a expressão princípio de proibição da retrogradação socioambiental, pois "retrogradar expressa melhor a idéia de retroceder, de ir para trás, no tempo e no espaço." A expressão proibição do retrocesso da lei ambiental prevalece entre os estudiosos e Prieur elucida que a utiliza no intuito de mostrar que não se trata de simples cláusula, mas de "um verdadeiro princípio geral do Direito Ambiental, na medida em que o que está em jogo é a salvaguarda dos progressos obtidos para evitar ou limitar a deterioração do meio ambiente." ${ }^{12}$ Utilizaremos esta expressão embasados no entendimento de Prieur, corroborado e pormenorizado pelo Ministro e professor Herman Benjamin $^{13}$ :

\footnotetext{
9 PRIEUR, Michel. O princípio da "não regressão" no coração do direito do homem e do meio ambiente. Novos Estudos Jurídicos, Itajaí, v.17, n 1, p. 6-17, 2012.

10 PRIEUR, Michel. O princípio da "não regressão" no coração do direito do homem e do meio ambiente. Novos Estudos Jurídicos, Itajaí, v.17, n 1, p. 6-17, 2012.

${ }^{11}$ MOLINARO, Carlos Alberto. Direito Ambiental: proibição de retrocesso. Porto Alegre: Livraria do Advogado Editora, 2007. p. 67.

12 PRIEUR, Michel. O princípio da "não regressão" no coração do direito do homem e do meio ambiente. Novos Estudos Jurídicos, Itajaí, v.17, n 1, p. 6-17, 2012.

13 BENJAMIN, Antônio Herman. Princípio da Proibição do Retrocesso Ambiental. Brasília: Senado Federal, 2011. p. 67.
} 
SCHNEIDER, Sabrina; RUSCHEL, Caroline Vieira. A violação do princípio da proibição do retrocesso da lei ambiental na região do Canto do Morcego, Itajaí - SC. Revista Eletrônica Direito e Política, Programa de Pós-Graduação Stricto Sensu em Ciência Jurídica da UNIVALI, Itajaí, v.10, n.1, edição especial de 2015. Disponível em: www.univali.br/direitoepolitica - ISSN 1980-7791.

É seguro afirmar que a proibição de retrocesso, apesar de não se encontrar, com nome e sobrenome, consagrada na nossa Constituição, nem em normas infraconstitucionais, e não obstante sua relativa imprecisão - compreensível em institutos de formulação recente e ainda em pleno processo de consolidação -, transformou-se em princípio geral do Direito Ambiental, a ser invocado na avaliação da legitimidade de iniciativas legislativas destinadas a reduzir o patamar de tutela legal do meio ambiente, mormente naquilo que afete em particular a) processos ecológicos essenciais, b) ecossistemas frágeis ou a beira de colapso, e c) espécies ameaçadas de extinção.

Como observado na própria terminologia, o princípio da proibição do retrocesso da lei ambiental não admite diminuição ou enfraquecimento no nível de promoção e proteção de um direito ${ }^{14}$.

Frente à necessidade latente em não se permitir recuo normativo na esfera ambiental, estudiosos do tema defendem que o princípio da proibição do retrocesso deve ser promovido como um novo princípio fundamental do Direito Ambiental. Prieur, um dos defensores da promoção do princípio a tal categoria, afirma que as bases da argumentação jurídica para tal repousam sobre três elementos:

a) O caráter finalista do Direito Ambiental: A finalidade do Direito Ambiental, como já observado anteriormente, não é apenas a regulamentação do meio ambiente; ainda tem como fim a contribuição à reação contra os processos de degradação ambiental e escassez dos recursos naturais. ${ }^{15}$ Prieur identifica em seus estudos que os princípios clássicos do Direito Ambiental podem ser facilmente interpretados como suporte ao princípio da proibição do retrocesso: a prevenção impede o recuo das proteções; a precaução - exemplo de regressão definitiva - permite que se evite a irreversibilidade; a participação permite um nível de proteção suficiente graças ao controle permanente dos cidadãos, dentre

\footnotetext{
${ }^{14}$ ROthenburg, Walter Claudius. Princípio da Proibição do Retrocesso Ambiental. Brasília: Senado Federal. p. 247.

${ }^{15}$ PRIEUR, Michel. Princípio da Proibição do Retrocesso Ambiental. Brasília: Senado Federal, 2011. p.16.
} 
SCHNEIDER, Sabrina; RUSCHEL, Caroline Vieira. A violação do princípio da proibição do retrocesso da lei ambiental na região do Canto do Morcego, Itajaí - SC. Revista Eletrônica Direito e Política, Programa de Pós-Graduação Stricto Sensu em Ciência Jurídica da UNIVALI, Itajaí, v.10, n.1, edição especial de 2015. Disponível em: www.univali.br/direitoepolitica - ISSN 1980-7791.

outros. ${ }^{16}$ Ainda há que se falar que um diploma criado com o objetivo claro de proteção a um ecossistema ou ser vivo específico, se modificado, perde a razão de ser; nas palavras de Prieur: "constitui um atentado direto à finalidade do texto inicial". ${ }^{17}$

b) Necessidade de se afastar o princípio da mutabilidade do Direito: o princípio da mutabilidade do Direito funda-se na idéia de que a geração presente não deve criar leis que irão reger o mundo de forma permanente, sujeitando as gerações futuras à suas regras e forma de ver o mundo - que se encontra em constante processo de transformação. Daí a idéia de que as leis caminhem no mesmo sentido, sendo modificadas de acordo com as mudanças sociais. Prieur defende que este pensamento seja modificado, afastando o princípio da mutabilidade das esferas humanas e ambientais - exceções à regra. Não impedir o retrocesso das leis ambientais teria como conseqüência a imposição à geração futura de um ambiente degradado. ${ }^{18}$

c) Intangibilidade dos direitos humanos: Prieur destaca que a finalidade dos direitos da Declaração Universal dos Direitos Humanos ${ }^{19}$ é a de favorecer o progresso social e instaurar melhores condições de vida. Completa afirmando que tal finalidade resulta em obrigações positivas para os Estados. ${ }^{20}$ Ainda atenta tal diploma para que cada indivíduo e órgão da sociedade se esforce "pela adoção de medidas progressivas de caráter nacional e internacional" ${ }^{21}$ no sentido de assegurar a observância e efetividade dos direitos ali elencados. $\mathrm{Na}$ qualitativa progressiva observa-se o desejo de avançar - "progressivo adj. 1.

${ }^{16}$ PRIEUR, Michel. Princípio da Proibição do Retrocesso Ambiental. Brasília: Senado Federal, 2011. p.16.

17 PRIEUR, Michel. Princípio da Proibição do Retrocesso Ambiental. Brasília: Senado Federal, 2011. p. 18.

${ }^{18}$ PRIEUR, Michel. Princípio da Proibição do Retrocesso Ambiental. Brasília: Senado Federal, 2011. p. 20.

19 Declaração Universal dos Direitos Humanos: <http://portal.mj.gov.br/sedh/ct/legis_intern/ddh_bib_inter_universal.htm>. Acesso em 11 mai. 2013.

20 PRIEUR, Michel. Princípio da Proibição do Retrocesso Ambiental. Brasília: Senado Federal, 2011. p. 20.

21 Declaração Universal dos Direitos Humanos: <http://portal.mj.gov.br/sedh/ct/legis_intern/ddh_bib_inter_universal.htm>. Acesso em 11 mai. 2013. 
SCHNEIDER, Sabrina; RUSCHEL, Caroline Vieira. A violação do princípio da proibição do retrocesso da lei ambiental na região do Canto do Morcego, Itajaí - SC. Revista Eletrônica Direito e Política, Programa de Pós-Graduação Stricto Sensu em Ciência Jurídica da UNIVALI, Itajaí, v.10, n.1, edição especial de 2015. Disponível em: www.univali.br/direitoepolitica - ISSN 1980-7791.

Que faz progressos, que progride. 2. Que avança lentamente, mas sem parar. 3. Que segue uma progressão." ${ }^{22}$ Tal análise demonstra que a proibição do retrocesso é mais do que implícita nos direitos humanos; o documento norteador dos direitos humanos básicos, clama por ações universais de caráter progressivo. Observa-se, portanto, que o direito ao meio ambiente, já consagrado como direito humano fundamental, pode ser alcançado pelo Princípio do Não Retrocesso através de um efeito de transbordamento da esfera social para a ambiental, claramente conectadas.

Denota-se de todos os debates a cerca da proteção das conquistas normativas na esfera ambiental, que o retrocesso de legislação fere o direito ao meio ambiente equilibrado, bem de uso comum do povo e essencial à sadia qualidade de vida, consagrado no caput do artigo 225 da Constituição da República Federativa do Brasil de $1988^{23}$ e reconhecidamente um Direito Fundamental de terceira geração. Aqui, abrem-se parênteses para sábia colocação sobre os direitos fundamentais realizada por José Afonso da Silva, afirmando que "se tratam de situações jurídicas sem as quais a pessoa humana não se realiza, não convive, às vezes nem sobrevive". ${ }^{24}$

\section{PRAIA BRAVA E O CANTO dO MORCEgo, ITAJAí SC: OCUPAÇÃo E DEGRADAÇÃO}

O município de Itajaí, situado na região do litoral norte de Santa Catarina, mais precisamente na Foz do Rio Itajaí Açu, possui 183.373 habitantes. ${ }^{25}$ Sua colonização se deu no século XVIII por portugueses e a partir daí surge a forte

\footnotetext{
22 Dicionário Priberam da Língua Portuguesa. Disponível em: <http://www.priberam.pt/dlpo/>. Acesso em 12 jun. 2013.

23 BRASIL. Constituição (1988). Constituição da República Federativa do Brasil. Brasília, DF, Senado, 1998.

24 SILVA, José Afonso da. Curso de Direito Constitucional Positivo. 13. ed. São Paulo: Malheiros, 1998. p. 176.

25 Dados Prefeitura Municipal de Itajaí, IBGE 2010. Disponível em: <http://www.ibge.gov.br/cidadesat/xtras/perfil.php?codmun=420820\&r=2>. Acesso em $13 \mathrm{mar}$. 2013.
} 
SCHNEIDER, Sabrina; RUSCHEL, Caroline Vieira. A violação do princípio da proibição do retrocesso da lei ambiental na região do Canto do Morcego, Itajaí - SC. Revista Eletrônica Direito e Política, Programa de Pós-Graduação Stricto Sensu em Ciência Jurídica da UNIVALI, Itajaí, v.10, n.1, edição especial de 2015. Disponível em: www.univali.br/direitoepolitica - ISSN 1980-7791.

ligação do município com o mar. ${ }^{26}$ Os frutos dessa colonização podem ser observados até hoje no município de Itajaí. Sua economia é baseada na atividade portuária; a cidade abriga um dos maiores complexos portuários do país. Ainda é conhecida como a capital brasileira da pesca, respondendo por $20 \%$ da produção brasileira de pescado. ${ }^{27}$

O município possui 6 praias; a mais extensa é a Praia Brava que está situada entre os promontórios rochosos da Praia do Morcego ao norte, e da Ponta da Preguiça ao Sul. Ao todo possui $2.980 \mathrm{~m}$ de extensão de faixa de areia. ${ }^{28}$ Trata-se de uma região com características que a tornam única, com a presença de ecossistemas costeiros específicos, como duna, restinga, Mata Atlântica, lagoa, manguezal e costões rochosos. ${ }^{29}$

Se atualmente a Praia Brava é a "menina dos olhos" do município devido às características únicas e grande beleza natural, em meados de 1970 - quando Itajaí passava por um intenso processo de remodelação e modernização urbana ${ }^{30}$ - esta localidade foi esquecida. Estudos demonstram que na década de 70 a Praia Brava era um local inóspito; o movimento na região se limitava à Estrada Geral, hoje conhecida como Rodovia Osvaldo Reis, que ainda permanece como principal via de ligação entre os Municípios de Itajaí e Balneário Camboriú. Existiam poucas residências próximas a orla; a rodovia abrigava prostíbulos e

\footnotetext{
${ }^{26}$ Estudos históricos revelam que em 1820 Dom João VI mandou trazer famílias de tradicionais pecadores portugueses da cidade de Ericeira para colonizar o litoral de Santa Catarina. Disponível em: <http://novo.itajai.sc.gov.br/c/historia>. Acesso em 13 mar. 2013.

27 Dados Prefeitura Municipal de Itajaí. Disponível em: <http://novo.itajai.sc.gov.br/c/historia>. Acesso em 13 mar. 2013.

28 POLETTE, M.; SARGenti, D.; DALBOSCO, R. Diagnóstico SocioAmbiental da Praia Brava. Programa de Restauração Ambiental e Ordenamento da Orla da Praia Brava: Relatório Final. Itajaí, 2005. p. 7.

29 POLETTE, M.; MARENZI, R. C.; SANTOS, C. F. dos. Atlas SocioAmbiental de Itajaí. Itajaí: Editora da UNIVALI, 2012. p. 44.

30 Segundo LUNA (2004) o prefeito Frederico Olindio de Souza, que cumpriu mandato entre os anos de 1973 a 1977 tinha como meta trazer o "progresso a Itajaí", e para que isso ocorresse sua equipe trabalhava intensamente na reforma da cidade.
} 
SCHNEIDER, Sabrina; RUSCHEL, Caroline Vieira. A violação do princípio da proibição do retrocesso da lei ambiental na região do Canto do Morcego, Itajaí - SC. Revista Eletrônica Direito e Política, Programa de Pós-Graduação Stricto Sensu em Ciência Jurídica da UNIVALI, Itajaí, v.10, n.1, edição especial de 2015. Disponível em: www.univali.br/direitoepolitica - ISSN 1980-7791.

atraía marginais em busca de esconderijos, além de moradores de baixa renda, que não vislumbravam a possibilidade de morar próximo ao centro da cidade. ${ }^{31}$

Apesar dos planos de urbanização municipal na década de 70 não contemplarem a Praia Brava, a modernização a atingiu de passagem devido à pavimentação da Rodovia Osvaldo Reis. ${ }^{32}$ Sua construção na década de 1970 foi possivelmente a principal obra que possibilitou tanto um aumento no turismo como um aumento populacional na região. ${ }^{33}$ A beleza e características agrestes da orla aliadas à proximidade com Balneário Camboriú - um dos balneários mais badalados do estado - e a chegada de facilidades da vida moderna como água, luz e pequenos comércios, tornaram a região um local valorizado e a partir da década de 1990, a Praia Brava se tornou o destino de pessoas que sonhavam em viver em uma região tranqüila a beira mar.

O Canto Norte da Praia Brava, região conhecida popularmente pelos frequentadores como Canto do Morcego, delimita-se a Leste com o Oceano Atlântico, a oeste com a Avenida Osvaldo Reis e Rua Teresa Francisca Pereira, ao sul com o Ribeirão do Cassino da Lagoa e ao norte com os bairros Fazenda e Cabeçudas, juntamente com o Morro do Farol e a Praia do Morcego. ${ }^{34}$

É uma região afetada de maneira menos intensa pela ocupação humana do que a porção Sul da Praia Brava; atualmente o Canto do Morcego é ocupado por três grandes bares, quatro estacionamentos, um quiosque e poucas residências, frutos de ocupações irregulares. Mesmo com a ocupação existente e a totalidade de seu solo já parcelado, o Canto Norte mantém a maior parte de seu território intocado. A região conserva grande parte das características originais da Praia Brava tratando-se, portanto, de um local com grande importância ecológica.

31 LUNA, Gloria Alejandra G. O processo de urbanização em Itajaí nos anos 70 e a Praia Brava. Revista Esboços. Florianópolis, v 11, n 11. p. 127-133, 2004.

32 LUNA, Gloria Alejandra G. O processo de urbanização em Itajaí nos anos 70 e a Praia Brava. Revista Esboços. Florianópolis, v 11, n 11. p. 127-133, 2004

33 POLETTE, M.; MARENZI, R. C.; SANTOS, C. F. dos. Atlas SocioAmbiental de Itajaí. Itajaí: Editora da UNIVALI, 2012. p. 45.

34 MARENZI, Rosemery Carvalho.Estudo sobre a viabilidade de implantação de uma Unidade de Conservação na Praia Brava (Itajaí, SC). Programa de Restauração Ambiental e Ordenamento da Orla da Praia Brava: Relatório Final. Itajaí, 2005. p. 99. 
SCHNEIDER, Sabrina; RUSCHEL, Caroline Vieira. A violação do princípio da proibição do retrocesso da lei ambiental na região do Canto do Morcego, Itajaí - SC. Revista Eletrônica Direito e Política, Programa de Pós-Graduação Stricto Sensu em Ciência Jurídica da UNIVALI, Itajaí, v.10, n.1, edição especial de 2015. Disponível em: www.univali.br/direitoepolitica - ISSN 1980-7791.

Contempla uma grande diversidade de ecossistemas: ambiente praial, complexo lagunar, manguezal, ambiente brejoso, restinga, floresta Atlântica e costões rochosos. $^{35}$

Neste cenário (Praia Brava) ocorre uma disputa territorial e social que se estende há pelo menos dez anos. Um diagnóstico realizado pelo Projeto Orla ${ }^{36}$ para a Prefeitura Municipal de Itajaí descreve tais conflitos:

Na Praia Brava podem ser observados diversos problemas de ordem ambiental, social e econômica, porém todos estão bastante inter relacionados, de tal maneira que poderiam ser agrupados em um único grande conflito: Ocupação e Uso privado da orla de maneira desordenada e sem fiscalização efetiva e a manutenção das características naturais, residenciais e rústicas da praia. Trata-se de um conflito de ocupação territorial (C.O.T), "gerado principalmente pela inadequação, inexistência ou ineficiência de normas e instrumentos de ordenamento do uso do solo na orla" .

Na porção norte da praia, região do Canto do Morcego, a disputa vem ganhando destaque e os atores e interesses se encontram numa batalha frontal para decidir a destinação adequada do local: de um lado os interessados em transformar a região ainda preservada da Praia Brava em unidade de conservação; do outro, empreendedores e o Poder Público Municipal que vislumbram para a região o turismo imobiliário destinado a um público de alto poder aquisitivo, fato que já ocorre no Canto Sul.

As tentativas frustradas de criação de uma lei de zoneamento que atenda as demandas de todos os atores envolvidos desde meados de 2008, confirmam o conflito e enquanto os atores não chegam a um consenso a região sofre a cada dia com a descaracterização de seu ambiente natural. Atualmente ocorre no local a construção de um empreendimento residencial, realizando supressão de vegetação nativa com licenças concedidas com base na Lei Ordinária no 2543 de

\footnotetext{
${ }^{35}$ MARENZI, Rosemery Carvalho.Estudo sobre a viabilidade de implantação de uma Unidade de Conservação na Praia Brava (Itajaí, SC). Programa de Restauração Ambiental e Ordenamento da Orla da Praia Brava: Relatório Final. Itajaí, 2005. p. 99.

${ }^{36}$ Ministério do Meio Ambiente, Ministério do Planejamento, Orçamento e Gestão. Projeto Orla: Fundamentos para gestão integrada. Brasília, 2006.
} 
SCHNEIDER, Sabrina; RUSCHEL, Caroline Vieira. A violação do princípio da proibição do retrocesso da lei ambiental na região do Canto do Morcego, Itajaí - SC. Revista Eletrônica Direito e Política, Programa de Pós-Graduação Stricto Sensu em Ciência Jurídica da UNIVALI, Itajaí, v.10, n.1, edição especial de 2015. Disponível em: www.univali.br/direitoepolitica - ISSN 1980-7791.

1989, a primeira Lei de Zoneamento aprovada no município e sem observância ao Plano diretor da cidade aprovado no ano de 2006.

Fato é que a referida região corre riscos de perder grande parte de seu sensível ecossistema em detrimento da construção civil, processo semelhante ao ocorrido no município de Balneário Camboriú, "onde a especulação imobiliária e a má administração levaram a quase completa extinção dos ecossistemas naturais presentes na praia ${ }^{37 . "}$

\section{ANÁLISE DAS LEIS COMPLEMENTARES No 94/2006 E No 215/2012}

\subsection{Breve Histórico}

Em 2001 foi aprovada a Lei Federal no 10.257, o Estatuto da Cidade, que estabeleceu um prazo de cinco anos para que os Planos Diretores das Cidades com mais de 20.000 habitantes pertencentes às regiões metropolitanas ou que se encontravam em regiões turísticas, fossem elaborados ou revisados de forma participativa, com audiências públicas e consultas populares. Esse prazo expirou em outubro de 2006; em 2005, Itajaí já havia iniciado o processo de revisão do seu Plano Diretor. Sua construção contou com a consultoria técnica de três Universidades; Universidade Federal de Santa Catarina (UFSC) que elaborou os Termos de Referência; Universidade do Vale do Itajaí (UNIVALI), que realizou a Leitura Técnica; Leitura Comunitária; Pactos e Propostas; Mapas Temáticos e Macrozoneamento Proposto ${ }^{38}$ e Universidade Regional de Blumenau (FURB), que realizou a revisão do Plano Diretor, consultoria que resultou no Projeto de Lei do Plano Diretor para ser submetido à aprovação do Poder Legislativo Municipal.

\footnotetext{
37 POlette, M.; SARGentI, D.; DALBOSCO, R. Diagnóstico SocioAmbiental da Praia Brava. Programa de Restauração Ambiental e Ordenamento da Orla da Praia Brava: Relatório Final. Itajaí, 2005. p.8.

38 SIEBERT, Claudia A. F. ENANPPAS - Encontro da Associação Nacional de Pesquisa e Pós Graduação em Ambiente e Sociedade, 4., 2008, Brasília - DF. Território em disputa: Santuário ou Filão Turístico Imobiliário? A Praia Brava de Itajai - SC. Brasília, 2008. Disponível em: <http://www.anppas.org.br/encontro4/cd/gt16.html>. Acesso em 29 mar. 2013.).
} 
SCHNEIDER, Sabrina; RUSCHEL, Caroline Vieira. A violação do princípio da proibição do retrocesso da lei ambiental na região do Canto do Morcego, Itajaí - SC. Revista Eletrônica Direito e Política, Programa de Pós-Graduação Stricto Sensu em Ciência Jurídica da UNIVALI, Itajaí, v.10, n.1, edição especial de 2015. Disponível em: www.univali.br/direitoepolitica - ISSN 1980-7791.

Importante frisar que o Projeto de Lei foi apreciado pelo Núcleo Gestor, que realizou alterações, inclusões e exclusões ao material antes da aprovação. ${ }^{39}$

Em estudo que relata a elaboração do Plano Diretor de Itajaí afirma-se que o processo ocorreu de forma a proporcionar a capacitação dos membros do Núcleo Gestor Territorial; tal capacitação permitiu aos conselheiros o empoderamento a cerca dos conteúdos necessários à elaboração da Lei, o que resultou numa participação efetiva e relevante ${ }^{40}$ :

As discussões resultaram na construção coletiva de um texto pactuado com o Núcleo Gestor, em uma experiência de planejamento participativo. Os membros do Núcleo Gestor demonstraram, durante a Oficina, comprometimento com o processo e senso de cidadania, na medida em que as discussões realizadas com uma grande participação de seus membros, somente finalizaram quando, de fato, chegou-se a um consenso [...] A avaliação da Oficina foi considerada positiva por todas as partes envolvidas, tanto as governamentais, como os diversos - e muitas vezes antagônicos - segmentos da sociedade civil.

No dia 22 de dezembro de 2006 foi aprovada a lei complementar no 94/2006 que institui o Plano Diretor de Gestão e Desenvolvimento Territorial de Itajaí, um "instrumento global e estratégico da política de desenvolvimento territorial, determinante para todos os agentes públicos e privados que atuam no Município". 41 A respectiva Lei estabelece dentre outros pontos de grande relevância, o macrozoneamento municipal. Ainda determina que "o Código de Zoneamento e Uso do Solo, o Código de Mobilidade, o Código de Parcelamento da Terra, o Código de Edificações e o Código de Posturas são leis

39 SIEBERT, Claudia A. F. ENANPPAS - Encontro da Associação Nacional de Pesquisa e Pós Graduação em Ambiente e Sociedade, 4., 2008, Brasília - DF. Território em disputa: Santuário ou Filão Turístico Imobiliário? A Praia Brava de Itajai - SC. Brasília, 2008. Disponível em: <http://www.anppas.org.br/encontro4/cd/gt16.html>. Acesso em 29 mar. 2013.

40 SIEBERT, Claudia A. F. ENANPPAS - Encontro da Associação Nacional de Pesquisa e Pós Graduação em Ambiente e Sociedade, 4., 2008, Brasília - DF. Território em disputa: Santuário ou Filão Turístico Imobiliário? A Praia Brava de Itajai - SC. Brasília, 2008. Disponível em: <http://www.anppas.org.br/encontro4/cd/gt16.html>. Acesso em 29 mar. 2013.)

${ }^{41}$ SANTA CATARINA. Lei Complementar n 94, de 22 de dezembro de 2006. Lex: Plano Diretor de Gestão e Desenvolvimento Territorial de Itajaí, Itajaí, 2006. 
SCHNEIDER, Sabrina; RUSCHEL, Caroline Vieira. A violação do princípio da proibição do retrocesso da lei ambiental na região do Canto do Morcego, Itajaí - SC. Revista Eletrônica Direito e Política, Programa de Pós-Graduação Stricto Sensu em Ciência Jurídica da UNIVALI, Itajaí, v.10, n.1, edição especial de 2015. Disponível em: www.univali.br/direitoepolitica - ISSN 1980-7791.

complementares a este Plano Diretor". ${ }^{42}$ A Lei Complementar no 94/2006 jamais foi questionada judicialmente, sendo talvez a participação popular capacitada e o consenso alcançado entre os diversos atores e interesses antagônicos, o motivo para tal.

Fato oposto ocorre com a lei que institui as normas para o Zoneamento e o uso do solo no município ${ }^{43}$, que vem sendo questionada judicialmente desde a sua primeira revisão. A aprovação de uma lei de zoneamento que substituiria a Lei Ordinária no 2543/1989, primeira Lei de Zoneamento municipal, aconteceu no ano de 2008. Aprovada sob o no 144/2008 teve no ano de 2011 sua inconstitucionalidade decretada por não observância ao Princípio da Participação.

A partir da declaração de inconstitucionalidade da Lei supra, iniciou-se um novo processo de revisão do zoneamento, construído por um Conselho Gestor Territorial ${ }^{44}$. O respectivo Conselho é alvo de críticas por parte do movimento socioambientalista local, que afirma que sua formação ocorreu sem a devida publicidade. Ainda o movimento aponta que sua composição conta com a predominância de atores do setor econômico ${ }^{45}$.

Aprovada como Lei Complementar no 215/2012 nos dias 21 e 31 de dezembro de 2012 respectivamente, o diploma rege o uso, a ocupação e o parcelamento do solo para fins urbanos, rurais e de preservação do município, "em conformidade com as determinações da Lei Orgânica e com as diretrizes estabelecidas no Plano

\footnotetext{
42 SANTA CATARINA. Lei Complementar n 94, de 22 de dezembro de 2006. Lex: Plano Diretor de Gestão e Desenvolvimento Territorial de Itajaí, Itajaí, 2006.

43 Lei que institui normas para o Zoneamento e uso do solo disponível em: <http://www.leismunicipais.com.br/a/sc/i/itajai/lei-complementar/2012/21/215/lei-complementarn-215-2012-institui-normas-para-o-codigo-de-zoneamento-parcelamento-e-uso-do-solo-nomunicipio-de-itajai-2012-12-31.html?wordkeytxt=215>. Acesso em 09 abr. 2013.

44 Conselho Gestor nomeado pelo Decreto n. 9250/10. Disponível em: <http://www.leismunicipais.com.br/a/sc/i/itajai/decreto/2010/925/9250/decreto-n-9250-2010nomeia-membros-do-conselho-municipal-de-gestao-e-desenvolvimento-territorial-2010-1119.html?wordkeytxt=9250>. Acesso em 08 jun. 2013.

45 Informações cedidas pela União dos Amigos da Brava - Unibrava, organização sem fins lucrativos, em 25 mar. 2013.
} 
SCHNEIDER, Sabrina; RUSCHEL, Caroline Vieira. A violação do princípio da proibição do retrocesso da lei ambiental na região do Canto do Morcego, Itajaí - SC. Revista Eletrônica Direito e Política, Programa de Pós-Graduação Stricto Sensu em Ciência Jurídica da UNIVALI, Itajaí, v.10, n.1, edição especial de 2015. Disponível em: www.univali.br/direitoepolitica - ISSN 1980-7791.

Diretor de Gestão e Desenvolvimento Territorial, observadas no que couber, as disposições da legislação federal e estadual pertinentes". ${ }^{46}$

Desde a data da aprovação, a respectiva Lei vem sendo questionada judicialmente. A Lei Complementar no 215/2006 é atualmente alvo de três ações distintas: uma Ação Popular ${ }^{47}$, impetrada por dois representantes do legislativo em janeiro de 2013, por ter sido aprovada em sessão na Câmara de Vereadores sem cumprimento de procedimentos regimentais; uma Ação Civil Pública ${ }^{48}$ de autoria do Ministério Público Estadual por entendê-la contrária ao Plano Diretor Municipal no que diz respeito à porção norte da Praia Brava, tendo esta ação a última decisão ${ }^{49}$ proferida até o momento; e por fim, uma Ação Direta de Inconstitucionalidade ${ }^{50}$, protocolada por cinco organizações da sociedade civil do município, em maio de 2013, por entenderem que além da não observância ao Plano Diretor durante a elaboração do zoneamento, a participação popular não ocorreu de forma plena.

\subsection{Análise das Leis Complementares n 94/2006 e n 215/2012 à luz do Princípio da Proibição do Retrocesso da Lei Ambiental}

Para que se dê continuidade ao presente estudo, é preciso que se estabeleçam dois conceitos no intuito de facilitar a compreensão da situação in loco: "área de preservação permanente" e "baixo impacto ambiental", visto que a região do Canto do Morcego é considerada no Plano Diretor do Município como Área de

\footnotetext{
46 SANTA CATARINA. Lei Complementar n 215, de 31 de dezembro de 2012. Lex: Código de Zoneamento, Parcelamento e Uso do Solo no Município de Itajaí, Itajaí, 2012.

47 Número do Processo: 033.13.000532-3. Encontra-se em grau de recurso e pode ser consultado no site <www.tj.sc.gov.br >. Acesso em 01 de jun. 2013.

48 Número do Processo: 033.13.007805-3. Pode ser consultado no site: <www.tj.sc.gov.br > Acesso em 01 de jun. 2013.

49 Decisão - Inteiro Teor disponível em: <http://esaj.tjsc.jus.br/cpo/pg/show.do?localPesquisa.cdLocal=33\&processo. codigo=0X0008RG00 $000 \&$ processo.foro $=33>$. Acesso em 01 de jun. 2013.

50 Número do Processo: 2013.032287-2. Pode ser consultado no site <www.tj.sc.gov.br >. Acesso em 03 de jun. 2013
} 
SCHNEIDER, Sabrina; RUSCHEL, Caroline Vieira. A violação do princípio da proibição do retrocesso da lei ambiental na região do Canto do Morcego, Itajaí - SC. Revista Eletrônica Direito e Política, Programa de Pós-Graduação Stricto Sensu em Ciência Jurídica da UNIVALI, Itajaí, v.10, n.1, edição especial de 2015. Disponível em: www.univali.br/direitoepolitica - ISSN 1980-7791.

Preservação Permanente ${ }^{51}$, permitindo em sua região somente atividades de baixo impacto.

A Lei no 12651 de 25 de maio de 2012, chamada de Novo Código Florestal ${ }^{52}$, apresenta em seu artigo 30, inciso II, a definição de Área de Preservação Permanente como área protegida, coberta ou não por vegetação nativa, que possui a função ambiental de preservar os recursos hídricos, a paisagem, a estabilidade geológica e a biodiversidade, bem como facilitar o fluxo gênico da fauna e da flora do local, a proteção do solo e o bem-estar das populações humanas. ${ }^{53}$ Complementando a definição apresentada pela referida lei, denotase a observação de Cavedon ${ }^{54}$ ao discorrer que a fixação de determinada vegetação pelo Código Florestal como de preservação permanente "[..] não se deu de forma aleatória. A vegetação é assim considerada pela função que desempenha para a proteção das áreas que reveste."

O Código Florestal prevê no Regime de Proteção das Áreas de Preservação Permanente, em seu artigo $8^{\circ}$ que "a intervenção ou a supressão de vegetação nativa em Área de Preservação Permanente somente ocorrerá nas hipóteses de utilidade pública, de interesse social ou de baixo impacto ambiental previstas nesta Lei." O termo "baixo impacto" e sua aplicação são discutidos amplamente pelos estudiosos do Direito e áreas transversais; não entraremos no mérito e utilizaremos no presente estudo o entendimento do Código Florestal $^{55}$, que dispõe em seu artigo $3^{\circ}$ o rol das atividades de baixo impacto.

Após breve aporte dos conceitos jurídicos dos termos supracitados, sob a ótica do objeto do presente estudo e da limitação geográfica pretendida, este capítulo versará sobre a divisão territorial do município em Macrozonas e Zonas,

${ }^{51}$ POLETTE, M.; SARgentI, D.; DALBOSCO, R. Diagnóstico SocioAmbiental da Praia Brava. Programa de Restauração Ambiental e Ordenamento da Orla da Praia Brava: Relatório Final. Itajaí, 2005. p. 8.

52 BRASIL. Lei n. 12.651 de 25 de maio de 2012. Lex: Código Florestal. Brasília, 2012.

${ }^{53}$ BRASIL. Lei n. 12.651 de 25 de maio de 2012. Lex: Código Florestal. Brasília, 2012.

${ }^{54}$ CAVEDON, Fernanda de Salles. Função social e ambiental da propriedade. Florianópolis: Visualbooks, 2003.

${ }^{55}$ BRASIL. Lei n. 12.651 de 25 de maio de 2012. Lex: Código Florestal. Brasília, 2012. 
SCHNEIDER, Sabrina; RUSCHEL, Caroline Vieira. A violação do princípio da proibição do retrocesso da lei ambiental na região do Canto do Morcego, Itajaí - SC. Revista Eletrônica Direito e Política, Programa de Pós-Graduação Stricto Sensu em Ciência Jurídica da UNIVALI, Itajaí, v.10, n.1, edição especial de 2015. Disponível em: www.univali.br/direitoepolitica - ISSN 1980-7791.

dispostas nas Leis Complementares no 94/2006 e no 215/2012 e seus respectivos mapas e anexos.

A Lei no 94/2006, Plano Diretor do Município, trata em seu texto, no Título IV, Capítulo II da Divisão Territorial, discorrendo que para orientar o ordenamento e a gestão territorial de Itajaí serão definidos o Macrozoneamento e o Zoneamento. O Macrozoneamento é definido no próprio Plano Diretor. O artigo $95^{56}$ da referida lei dispõe que sua finalidade é a definição de diretrizes para orientar o desenvolvimento de acordo com as características físicas, sociais, culturais, econômicas e ambientais de cada região, de forma que promova o desenvolvimento harmônico do município e o bem estar dos munícipes. Os incisos do respectivo artigo apresentam as sete Macrozonas definidas para o município de Itajaí, dentre elas a MZPA, "Macrozona de Proteção Ambiental, destinada a usos de baixo impacto que não conflitem com a preservação ambiental e cultural à preservação ambiental permanente. ${ }^{\prime 57}$ No mapa de Macrozoneamento do Plano Diretor de Itajaíis, que apresenta as Macrozonas do município, a região do Canto do Morcego se encontra na área definida como MZPA - Macrozona de Proteção Ambiental.

A Lei de Zoneamento no 215/2012 entende o Zoneamento como a divisão do território municipal com vistas a dar a cada região melhor utilização em função da malha viária, da topografia e da infra-estrutura existente, através da criação de zonas e setores de uso e ocupação do solo. ${ }^{59}$ Em seu Capítulo III trata de maneira específica do Código de Zoneamento, instituindo regras gerais de uso,

\footnotetext{
${ }^{56}$ SANTA CATARINA. Lei Complementar n 94, de 22 de dezembro de 2006. Lex: Plano Diretor de Gestão e Desenvolvimento Territorial de Itajaí, Itajaí, 2006.

57 SANTA CATARINA. Lei Complementar n 94, de 22 de dezembro de 2006. Lex: Plano Diretor de Gestão e Desenvolvimento Territorial de Itajaí, Itajaí, 2006.

58 Mapa de Macrozoneamento do Plano Diretor de Itajaí disponível em: <http://novo.itajai.sc.gov.br/l/mapa>. Acesso em 25 mar. 2013.

59 SANTA CATARINA. Lei Complementar n 215, de 31 de dezembro de 2012. Lex: Código de Zoneamento, Parcelamento e Uso do Solo no Município de Itajaí, Itajaí, 2012.
} 
SCHNEIDER, Sabrina; RUSCHEL, Caroline Vieira. A violação do princípio da proibição do retrocesso da lei ambiental na região do Canto do Morcego, Itajaí - SC. Revista Eletrônica Direito e Política, Programa de Pós-Graduação Stricto Sensu em Ciência Jurídica da UNIVALI, Itajaí, v.10, n.1, edição especial de 2015. Disponível em: www.univali.br/direitoepolitica - ISSN 1980-7791.

ocupação e parcelamento do solo para as Zonas - subdivisões das Macrozonas, das quais possui o dever de seguir as determinações. ${ }^{60}$

Ocorre que a Região do Canto do Morcego, classificada como Macrozona de Proteção Ambiental no Plano Diretor, foi subdividida na Lei de Zoneamento no 215/2012, passando a incorporar uma Zona denominada ZEA - Zona Especial Ambiental. O artigo 39 da Lei de Zoneamento no 215/2012, apresenta a ZEA como "área em região urbana litorânea, possuindo restrições quanto aos seus usos e parâmetros construtivos" ${ }^{\prime 1}$; posteriormente, em seu parágrafo único, dispões suas limitações geográficas. Contudo, a ZEA - Zona Especial Ambiental encontra-se, segundo a Lei no 215/2012, artigo 31, parágrafo único, em uma Macrozona Urbana, além de apresentar como sigla no referido artigo as letras $Z R A$, não estando de acordo com sua definição e com o Mapa de Zoneamento, o que poderia induzir o leitor a entender a referida zona como Residencial, como as zonas posteriores que apresentam a letra $R$ em suas siglas, correspondentes à palavra Residencial ${ }^{62}$ :

\section{SEÇÃO DA MACROZONA URBANA II}

Art. 31

Parágrafo Único. Subdivide-se em:

$[\ldots]$

VI - ZRE - Zona Especial Ambiental

VII - ZR1 - Zona Residencial 01

VIII - ZR2 - Zona Residencial 02

IX - ZR3 - Zona Residencial 03

X - ZIT - Zona de Interesse Turístico

\footnotetext{
60 SANTA CATARINA. Lei Complementar n 215, de 31 de dezembro de 2012. Lex: Código de Zoneamento, Parcelamento e Uso do Solo no Município de Itajaí, Itajaí, 2012.

61 SANTA CATARINA. Lei Complementar n 215, de 31 de dezembro de 2012. Lex: Código de Zoneamento, Parcelamento e Uso do Solo no Município de Itajaí, Itajaí, 2012.

62 SANTA CATARINA. Lei Complementar n 215, de 31 de dezembro de 2012. Lex: Código de Zoneamento, Parcelamento e Uso do Solo no Município de Itajaí, Itajaí, 2012).
} 
SCHNEIDER, Sabrina; RUSCHEL, Caroline Vieira. A violação do princípio da proibição do retrocesso da lei ambiental na região do Canto do Morcego, Itajaí - SC. Revista Eletrônica Direito e Política, Programa de Pós-Graduação Stricto Sensu em Ciência Jurídica da UNIVALI, Itajaí, v.10, n.1, edição especial de 2015. Disponível em: www.univali.br/direitoepolitica - ISSN 1980-7791.

$$
\begin{aligned}
& \text { XI - ZEU - Zona de Expansão Urbana } \\
& \text { XII - ZC1 - Zona Central } 1 \\
& \text { XIII - ZC2 - Zona Central } 2
\end{aligned}
$$

O referido dispositivo demonstra não estar de acordo com o Plano Diretor, o que fere seu próprio texto, que dispõe no artigo 13 que o Código de Zoneamento estabelece áreas diferenciadas de uso e ocupação do solo, "seguindo as determinações do Macrozoneamento definidas pelo Plano Diretor do Município". ${ }^{63}$ Nos mapas de Macrozona do Plano Diretor e do Código de Zoneamento, parcelamento e uso do solo é possível observar que a ZEA - Zona Especial Ambiental criada na Lei de Zoneamento está claramente inserida na MZPA Macrozona de Proteção Ambiental do Plano Diretor, e não na Macrozona Urbana como dispõe o artigo supracitado da Lei de Zoneamento no 215/2012.

Fato é que a incongruência entre as legislações, que deveriam ser complementares entre si, modifica completamente as permissões de zoneamento e uso do solo na região. Enquanto o Plano de Diretor no 94/2006 permite no Canto do Morcego somente atividades de baixo impacto "que não conflitem com a preservação ambiental e cultural à preservação ambiental permanente" ${ }^{64}$, a Lei de Zoneamento, parcelamento e uso do solo apresenta como usos permitidos na Tabela de Parâmetros de zoneamento e uso do solo: Habitação Unifamiliar; habitação multifamiliar; comunitário; comercial e de serviço. ${ }^{65}$ Destacam-se os usos permissíveis: ${ }^{66}$ comércio e serviços de bairro; comércios e serviços setoriais e comércios e serviços específicos. Ainda a tabela apresenta seis pavimentos como altura máxima das edificações permitidas para a área, dentre outros

\footnotetext{
63 SANTA CATARINA. Lei Complementar n 215, de 31 de dezembro de 2012. Lex: Código de Zoneamento, Parcelamento e Uso do Solo no Município de Itajaí, Itajaí, 2012.

64 SANTA CATARINA. Lei Complementar n 94, de 22 de dezembro de 2006. Lex: Plano Diretor de Gestão e Desenvolvimento Territorial de Itajaí, Itajaí, 2006.

65 SANTA CATARINA. Lei Complementar n 215, de 31 de dezembro de 2012. Lex: Código de Zoneamento, Parcelamento e Uso do Solo no Município de Itajaí, Itajaí, 2012.

66 SANTA CATARINA. Lei Complementar n 215, de 31 de dezembro de 2012. Lex: Código de Zoneamento, Parcelamento e Uso do Solo no Município de Itajaí, Itajaí, 2012.
} 
SCHNEIDER, Sabrina; RUSCHEL, Caroline Vieira. A violação do princípio da proibição do retrocesso da lei ambiental na região do Canto do Morcego, Itajaí - SC. Revista Eletrônica Direito e Política, Programa de Pós-Graduação Stricto Sensu em Ciência Jurídica da UNIVALI, Itajaí, v.10, n.1, edição especial de 2015. Disponível em: www.univali.br/direitoepolitica - ISSN 1980-7791.

parâmetros como taxa de ocupação dos lotes, recuos das construções e taxa de permeabilidade. ${ }^{67}$

Do exposto pode-se afirmar que o retrocesso ocorre a partir da criação da Lei de Zoneamento no 215/2012, que ao subdividir a MZPA - Macrozona de Proteção Ambiental delimitada no Plano Diretor no 94/2006 em ZEA - Zona Especial Ambiental, acarreta para a região do Canto do Morcego permissões outrora impensáveis para uma Área de Preservação Permanente.

Ainda denota-se do exposto que o Conselho Gestor, ao elaborar a Lei de Zoneamento no 215/2012 sob a supervisão da Secretaria Municipal de Urbanismo, levou em consideração o potencial turístico da região, interesse maior dos empreendedores da construção civil, proprietários dos terrenos localizados no Canto do Morcego e Poder Público, em detrimento da manutenção de seu ecossistema e consequentemente, do direito difuso ao meio ambiente equilibrado. Nessa esteira, preleciona Prieur ${ }^{68}$ :

O que está em jogo aqui é a vontade de suprimir uma regra (constituição, lei ou decreto) ou de reduzir seus aportes em nome de interesses, claros ou dissimulados, tidos como superiores aos interesses ligados à proteção ambiental. A mudança da regra que conduz a uma regressão constitui um atentado direto à finalidade do texto inicial. O retrocesso em matéria ambiental não é imaginável. Não se pode considerar uma lei que, brutalmente, revogue normas antipoluição ou normas sobre a proteção da natureza; ou, ainda, que suprima, sem justificativa, áreas ambientalmente protegidas. É de se notar, ainda, que a regressão do Direito Ambiental

será sempre insidiosa e discreta, para que passe despercebida. $\mathrm{E}$, por isso, ela se torna ainda mais perigosa. Os retrocessos discretos ameaçam todo o DireitoAmbiental.

67 SANTA CATARINA. Lei Complementar n 215, de 31 de dezembro de 2012. Lex: Código de Zoneamento, Parcelamento e Uso do Solo no Município de Itajaí, Itajaí, 2012.

68 PRIEUR, Michel. Princípio da Proibição do Retrocesso Ambiental. Brasília: Senado Federal, 2011. p. 20. 
SCHNEIDER, Sabrina; RUSCHEL, Caroline Vieira. A violação do princípio da proibição do retrocesso da lei ambiental na região do Canto do Morcego, Itajaí - SC. Revista Eletrônica Direito e Política, Programa de Pós-Graduação Stricto Sensu em Ciência Jurídica da UNIVALI, Itajaí, v.10, n.1, edição especial de 2015. Disponível em: www.univali.br/direitoepolitica - ISSN 1980-7791.

\section{CONSIDERAÇÕES FINAIS}

O princípio da proibição do retrocesso da Lei Ambiental garante a não regressão de proteção outrora conferida a um direito difuso e fundamental à existência da Humanidade, o direito ao meio ambiente; mais do que isso, é dever que se impõe à Administração de não andar para trás, garantindo às futuras gerações uma vida plena em seus direitos mais fundamentais.

Nesse contexto, e frente às informações suscitadas, resta claro que a aprovação da Lei de Zoneamento no 215/2012 causou um grave retrocesso na proteção anteriormente conferida à região do Canto do Morcego pelo Plano Diretor no 94/2006. A região, reconhecida nesta última como APP - Área de Preservação Permanente, permitindo, portanto, somente atividades de baixo impacto ambiental, se vê ameaçada pela legislação posteriormente aprovada, a Lei de Zoneamento no 215/2012, que permite uma série de usos em detrimento da proteção de seu valioso ecossistema.

Das incongruências que a Lei de Zoneamento no 215/2012 apresenta com relação à região do Canto do Morcego, destaca-se a criação de uma Zona Residencial inserida numa Macrozona de Preservação Ambiental, modificando completamente o uso do solo no local. A região, classificada como MZPA Macrozona de Proteção Ambiental no Plano Diretor Municipal n o 94/2006, já se encontra em processo de uso contrário ao permitido para o tipo de vegetação; atualmente o local é explorado pela construção civil, o que causa impactos ambientais negativos para a flora e fauna da região, consideradas únicas por estudos e pela própria Lei n 0 94/2006.

A Lei de Zoneamento n 0 215/2012, não somente fere as intenções iniciais que o Plano Diretor tinha para com a região ao não seguir suas determinações; fere a proteção conferida pelo Código Florestal devido ao seu status de APP - Área de Preservação Permanente bem como o artigo 225, da Constituição da República Federativa do Brasil de $1988^{69}$, como o fez com vistas a atender interesses claros de determinados atores do conflito existente na região. Tais intenções, a

${ }^{69}$ BRASIL. Constituição da República Federativa do Brasil. Brasília, DF, Senado, 1998. 
SCHNEIDER, Sabrina; RUSCHEL, Caroline Vieira. A violação do princípio da proibição do retrocesso da lei ambiental na região do Canto do Morcego, Itajaí - SC. Revista Eletrônica Direito e Política, Programa de Pós-Graduação Stricto Sensu em Ciência Jurídica da UNIVALI, Itajaí, v.10, n.1, edição especial de 2015. Disponível em: www.univali.br/direitoepolitica - ISSN 1980-7791.

princípio veladas, podem ser claramente identificadas na tentativa de inserir no texto da Lei de Zoneamento no 215/2012 a Zona Especial Ambiental numa Macrozona Urbana e na sigla ZRE que não corresponde à Zona Especial Ambiental - induzindo o leitor a entendê-la como zona residencial - e intensificam ainda mais o conflito e discussões a cerca da região do Canto do Morcego, que vê diminuir a cada dia seu valioso ecossistema devido ao retrocesso da proteção conferida pelo Plano Diretor Municipal, ocasionado pela aprovação posterior da Lei Complementar no 215/2012.

\section{REFERÊNCIAS BIBLIOGRÁFICAS}

BenJAmin, Antônio Herman. Princípio da Proibição do Retrocesso Ambiental. Brasília: Senado Federal, 2011.

BOBBIO, Norberto. A era dos direitos. Tradutor: Carlos Nelson Coutinho.8. ed. Rio de Janeiro: Campus/Elsevier, 1992.

CAVEDON, Fernanda de Salles. Função social e ambiental da propriedade. Florianópolis: Visualbooks, 2003.

LUNA, Gloria Alejandra G. O processo de urbanização em Itajaí nos anos 70 e a Praia Brava. Revista Esboços. Florianópolis, v 11, n 11. p. 127-133, 2004.

MARENZI, Rosemery Carvalho. Estudo sobre a viabilidade de implantação de uma Unidade de Conservação na Praia Brava (Itajaí, SC). Programa de Restauração Ambiental e Ordenamento da Orla da Praia Brava: Relatório Final. Itajaí, 2005.

Ministério do Meio Ambiente, Ministério do Planejamento, Orçamento e Gestão. Projeto Orla: Fundamentos para gestão integrada. Brasília, 2006.

MOLINARO, Carlos Alberto. Direito Ambiental: proibição de retrocesso. Porto Alegre: Livraria do Advogado Editora, 2007. 
SCHNEIDER, Sabrina; RUSCHEL, Caroline Vieira. A violação do princípio da proibição do retrocesso da lei ambiental na região do Canto do Morcego, Itajaí - SC. Revista Eletrônica Direito e Política, Programa de Pós-Graduação Stricto Sensu em Ciência Jurídica da UNIVALI, Itajaí, v.10, n.1, edição especial de 2015. Disponível em: www.univali.br/direitoepolitica - ISSN 1980-7791.

POLETTE, M.; MARENZI, R. C.; SANTOS, C. F. dos. Atlas SocioAmbiental de Itajaí. Itajaí: Editora da UNIVALI, 2012.

POLETTE, M.; SARGENTI, D.; DALBOSCO, R. Diagnóstico SocioAmbiental da Praia Brava. Programa de Restauração Ambiental e Ordenamento da Orla da Praia Brava: Relatório Final. Itajaí, 2005.

PRIEUR, Michel. O princípio da "não regressão" no coração do direito do homem e do meio ambiente. Novos Estudos Jurídicos, Local da Publicação, v. 17, n. 1, 2012.

PRIEUR, Michel. Princípio da Proibição do Retrocesso Ambiental. Brasília: Senado Federal, 2011.

Projeto de Gestão Integrada da Orla Marítima: Projeto Orla Itajaí. Brasília: MMA e MPO, 2004. 73p.

ROThenbuRg, Walter Claudius. Princípio da Proibição do Retrocesso Ambiental. Brasília: Senado Federal, 2011.

SANTA CATARINA. Lei Complementar n 94, de 22 de dezembro de 2006. Lex: Plano Diretor de Gestão e Desenvolvimento Territorial de Itajaí, Itajaí, 2006.

SANTA CATARINA. Lei Complementar n 215, de 31 de dezembro de 2012. Lex: Código de Zoneamento, Parcelamento e Uso do Solo no Município de Itajaí, Itajaí, 2012.

SIEBERT, Claudia A. F. ENANPPAS - Encontro da Associação Nacional de Pesquisa e Pós Graduação em Ambiente e Sociedade, 4., 2008, Brasília - DF. Território em disputa: Santuário ou Filão Turístico Imobiliário? A Praia Brava de Itajai - SC. Brasília, 2008. Disponível em: <http://www.anppas.org.br/encontro4/cd/gt16.html>. Acesso em 29 mar. 2013.

SILVA, José Afonso da. Curso de Direito Constitucional Positivo. 13. ed. São Paulo: Malheiros, 1998. 
SCHNEIDER, Sabrina; RUSCHEL, Caroline Vieira. A violação do princípio da proibição do retrocesso da lei ambiental na região do Canto do Morcego, Itajaí - SC. Revista Eletrônica Direito e Política, Programa de Pós-Graduação Stricto Sensu em Ciência Jurídica da UNIVALI, Itajaí, v.10, n.1, edição especial de 2015. Disponível em: www.univali.br/direitoepolitica - ISSN 1980-7791.

Prefeitura Municipal de $\quad$ Itajaí $\quad$ História

<http://novo.itajai.sc.gov.br/c/historia>

Prefeitura Municipal de Itajaí - Mapas <http://novo.itajai.sc.gov.br/l/mapa> Portal do Ministério da Justiça <http://portal.mj.gov.br/sedh/ct/legis_intern/ddh_bib_inter_universal.htm >

Instituto Brasileiro de Geografia e Estatística - IBGE <http://www.ibge.gov.br/cidadesat/xtras/perfil.php?codmun=420820\&r=2>.

\section{Lei Complementar no 215 de 31 de dezembro de 2012} <http://www.leismunicipais.com.br/a/sc/i/itajai/leicomplementar/2012/21/215/lei-complementar-n-215-2012-institui-normaspara-o-codigo-de-zoneamento-parcelamento-e-uso-do-solo-no-municipio-deitajai-2012-12-31.html?wordkeytxt=215>

A ONU e o Meio Ambiente <http://www.onu.org.br/a-onu-em-acao/a-onu-e-omeio-ambiente/>

Dicionário Priberam <http://www.priberam.pt/dlpo/>

Submetido em: Setembro/2014

Aprovado em: Outubro/2014 